Article

\title{
Amelioration of Composts for Greenhouse Vegetable Plants Using Pasteurised Agaricus Mushroom Substrate
}

\author{
Ketil Stoknes ${ }^{1, *(\mathbb{D}}$, Ewelina Wojciechowska ${ }^{2}$, Agnieszka Jasinska ${ }^{1,3}\left(\mathbb{D}\right.$ and Ralph Noble ${ }^{4}$ \\ 1 Lindum AS, 3036 Drammen, Norway; jasinska.a@gmail.com \\ 2 Norwegian Institute of Bioeconomy Research (NIBIO), Ås 1431 Troms $\varnothing$, Norway; \\ ewelina.wojciechowska@nibio.no \\ 3 Department of Vegetable Crops, Faculty of Horticulture, Poznan University of Life Sciences, \\ 60-594 Poznań, Poland \\ 4 Pershore College, Warwickshire College Group, Pershore WR10 3JP, UK; rnoble@warwickshire.ac.uk \\ * Correspondence: ketil.stoknes@lindum.no
}

Received: 4 November 2019; Accepted: 25 November 2019; Published: 29 November 2019

\begin{abstract}
When using food and green waste composts as peat-free plant growing media, there is a challenge that nutrient immobilisation and high $\mathrm{pH}$ and salts content limit plant growth. The present study explored the use of spent mushroom compost (SMC) of Agaricus subrufescens in a sustainable plant growing system where only vermicompost from digested food waste and composted green wastes were used, even for the seedling stage. However, negative effects of high compost inclusion were offset by adding SMC. Significantly higher plant yield was obtained in several of the SMC amended treatments in four out of five lettuce experiments and in one tomato experiment. In addition, an experiment with cucumbers showed that nutrients were not available to the plant when the mushroom mycelium was actively growing, but became available if the mushroom mycelium had been inactivated first by pasteurisation. A significant effect from SMC was not observed under full fertigation. This study demonstrated that the addition of pasteurised Agaricus mycelium colonised compost can successfully offset negative effects from high $\mathrm{pH}$ and EC as well as limited nutrient supply (and nitrogen immobilisation) in peat-free, compost-based growing media.
\end{abstract}

Keywords: peat-free growing media; spent mushroom compost; sustainable horticulture; vermicompost; green waste; urban agriculture; vegetable cultivation; digestate

\section{Introduction}

Soilless cultivation systems support resource use efficiency and crop quality [1]. Peat has been very popular as a substrate for decades due to its high conformity and excellent properties [2]. However, it is a fossil material contributing to global carbon emissions, and its extraction is environmentally problematic in several aspects at the local scale [3-5], whereas using inorganic growing media in such systems is not circular, since they end up as wastes after use [6]. Organic growing media are easier to recycle. Therefore, compost from waste materials is being increasingly adopted as peat substitute. Among the challenges of including a high percentage of compost in growing media are high $\mathrm{pH}$, high salinity and nitrogen immobilisation [7-9].

Using spent mushroom compost (SMC) in growing media has been extensively studied. Most studies were motivated by the need to dispose of large quantities of SMC from Agaricus and Pleurotus sp. cultivation, while simultaneously obtaining substitutes for more expensive or environmentally problematic growing media, such as peat $[10,11]$. However, there is consensus that a major challenge with fresh untreated SMC is its high salt content. Plants, especially seedlings, 
are sensitive to the high EC (electrical conductivity) in SMC. Therefore, the majority of studies have found a reduced germination or growth when mixing increasing amounts of SMC into commercial growing media $[10,12,13]$. However, stronger growth of tomato and cucumber in peat was achieved with addition of SMC of enoki (Flammulina velutipes (Curtis) Singer) [14] and oyster mushrooms (Pleurotus ostreatus (Jacq.) P. Kumm.) [15]. SMC of the common button mushroom (Agaricus bisporus Lange) stimulated growth of shrubs in peat [16], of Euphorbia in peat-perlite mix [11] and of pepper (Capsicum) in soil [17]. SMC of the tropical mushroom species Agaricus subrufescens Peck [1894] (syn.: A. brasiliensis Wasser, M. Didukh, Amazonas \& Stamets, A. blazei Murrill), stimulated growth of lettuce in mineral soil [18] and in bark-vermiculite mix [19], and increased yields from tomato plants propagated in bark-vermiculite [20]. A. subrufescens can be grown in greenhouses on compost made with straw and digestate [21].

The present study explored the possibility to integrate mushroom and vegetable cultivation more directly by investigating if SMC of A. subrufescens could also improve growth of vegetables in a sustainable peat-free system, when combined with green waste compost, vermicompost from solids of food waste digestate, and fertigation with liquid food waste digestate. In this system, the main growing medium component is green waste compost. Even though the vermicompost increases nitrogen availability, vegetable plants could benefit from the additional nutrient supply or improved nutrient release from addition of SMC.

In fact, such investigations raise questions that are more fundamental: Can cultivable fungi be utilised to lower $\mathrm{pH}$ in high $\mathrm{pH}$ composts? Is the stimulating effect related to mineralisation and release of nutrients from the organic materials? Would SMC be more or less effective if inactivated by pasteurisation? An explorative series of experiments were performed, motivated by these questions.

\section{Materials and Methods}

Seven independent plant growth trials were performed, using different batches of materials, in which SMC was added to compost mixes, or to commercial peat substrates used as controls (Table 1). Inclusion rates of SMC below $30 \%$ by volume were used.

\subsection{Substrates}

SMCs originated from mushroom composts made from wheat straw, food waste digestate and gypsum, on which mushroom harvesting was terminated before use in the plant experiments. The SMC originated from the cultivation of A. subrufescens (strain M7700; Mycelia, Nevele, Belgium) unless stated otherwise, where Agaricus bisporus Lange (var. hortensis, strain M7243) and Agaricus bitorquis (Quél.) Sacc. (strain M7300), same supplier, were used. Casing, a mixture of peat and lime (Wokas, PL) was included with the SMC. In the combined experiment, fresh mushroom compost ("Phase III", not previously used for mushroom production) was used instead of SMC. Mushroom compost preparation and cultivation procedures followed Stoknes et al. [21]. Green waste compost (GC) was produced from a mix of municipal park and household garden waste in a commercial composting yard, where the waste was ground up, and then composted for up to one year in turned windrows until full maturity. The process also involved separation of larger woody parts by screening at one or two stages. Vermicompost made from food waste digestate (VC) was combined with GC in all compost treatments in order to provide more available nitrogen and stimulate plant growth. Pure peat (von Post H2-4 from Holmen Torv, NO), commercial (fertilised and limed) peat substrate (Veksttorv Grov, Norgro, NO) and perlite (Grain 3, Pull Rhenen, NL) were also used. Proportions are reported in Table 1. Analysis of SMC and raw materials is given in Table 2. Liquid digestate (used for organic fertigation) was rich in $\mathrm{NH}_{4}-\mathrm{N}$, organic $\mathrm{N}$, organic material, $\mathrm{Na}$ and $\mathrm{Cl}$ compared to standard mineral fertilisers. More details on the liquid digestate were reported by Stoknes et al. [22]. 
Table 1. Overview of experiments, number of replicates and treatments. SMC = Spent mushroom compost; A. sub. = Agaricus subrufescens; bis. = bisporus; bit. = bitorquis

\begin{tabular}{|c|c|c|c|c|c|c|c|c|c|c|c|}
\hline \multirow{2}{*}{ Experiment } & \multirow[b]{2}{*}{ Treatments } & \multirow{2}{*}{$\begin{array}{l}\text { Number of } \\
\text { Replicates }\end{array}$} & \multicolumn{8}{|c|}{ Composition by Volume (\%) } & \multirow[b]{2}{*}{ Fertigation } \\
\hline & & & $\begin{array}{l}\text { Green Waste } \\
\text { Compost }\end{array}$ & Vermi-compost & $\begin{array}{l}\text { Commercial } \\
\text { Fertilised Peat }\end{array}$ & Peat & Perlite & $\begin{array}{l}\text { A.sub. } \\
\text { SMC }\end{array}$ & $\begin{array}{c}\text { Pasteur. } \\
\text { A.sub. SMC }\end{array}$ & $\begin{array}{l}\text { A.bis. } \\
\text { SMC }\end{array}$ & \\
\hline \multirow{5}{*}{ Lettuce 1} & A Compost mix & & 91 & 9 & & & & & & & \multirow{5}{*}{$\begin{array}{c}\text { Digestate } \\
\mathrm{EC}=1.5 \mathrm{mS} \mathrm{cm}^{-1}\end{array}$} \\
\hline & B Comp $+4 \%$ SMC & & 87 & 9 & & & & 4 & & & \\
\hline & C Comp $+8 \%$ SMC & 10 & 84 & 8 & & & & 8 & & & \\
\hline & D Comp $+15 \%$ SMC & & 77 & 8 & & & & 15 & & & \\
\hline & E Comp $+25 \%$ SMC & & 63 & 12 & & & & 25 & & & \\
\hline \multirow{5}{*}{ Lettuce 2} & A Peat & \multirow{5}{*}{22} & & & 100 & & & & \multirow{5}{*}{10} & & \multirow{5}{*}{$\begin{array}{c}\text { Mineral } \\
\mathrm{EC}=2.3 \mathrm{mS} \mathrm{cm}^{-1}\end{array}$} \\
\hline & B Peat + AsubSMC & & & & 90 & & & 10 & & & \\
\hline & C Peat + past AsubSMC & & & & 90 & & & & & & \\
\hline & D Peat + AbitSMC & & & & 90 & & & & & $10^{\mathrm{I}}$ & \\
\hline & E Peat $+\min$ AsubSMC & & & & 98 & & & $2^{\mathrm{II}}$ & & & \\
\hline \multirow{6}{*}{ Lettuce 3} & A Peat & \multirow{6}{*}{6} & & & 100 & & & & \multirow{6}{*}{10} & & \multirow{6}{*}{ no } \\
\hline & B Peat + SMC & & & & 90 & & & 10 & & & \\
\hline & C Comp low + SMC & & 50 & 20 & & 20 & & 10 & & & \\
\hline & D Comp low + past SMC & & 50 & 20 & & 20 & & & & & \\
\hline & E Comp high + SMC & & 30 & 40 & & 15 & 5 & 10 & & & \\
\hline & F Comp high & & 30 & 40 & & 20 & 10 & & & & \\
\hline \multirow{8}{*}{ Lettuce 4} & A Peat & \multirow{8}{*}{8} & & & 100 & & & & \multirow{8}{*}{$2^{\mathrm{III}}$} & & \multirow{8}{*}{$\begin{array}{l}\text { Digestate } \\
\mathrm{EC}=2.5 \\
\mathrm{mS} \mathrm{cm}^{-1} \\
\text { on half of the } \\
\text { replicate pots }\end{array}$} \\
\hline & B Peat + Asub SMC & & & & 80 & & & 20 & & & \\
\hline & C Compost mix & & 60 & 40 & & & & & & & \\
\hline & D Comp + Asub SMC & & 40 & 40 & & & & 20 & & & \\
\hline & E Comp + past Asub SMC & & 40 & 40 & & & & & & & \\
\hline & F Comp + Asub spawn & & 58 & 40 & & & & $2^{\mathrm{III}}$ & & & \\
\hline & G Comp +pastAsub spawn & & 58 & 40 & & & & & & & \\
\hline & H Comp + Abis spawn & & 58 & 40 & & & & & & $2^{\mathrm{III}}$ & \\
\hline \multirow{8}{*}{ Lettuce 5} & A Peat & \multirow{8}{*}{20} & & & 100 & & & & \multirow[b]{8}{*}{20} & & \multirow{8}{*}{ no } \\
\hline & B Peat + Asub SMC & & & & 80 & & & 20 & & & \\
\hline & C Peat + Abis SMC & & & & 80 & & & & & 20 & \\
\hline & D Peat + past Abis SMC & & & & 80 & & & & & $20 \mathrm{IV}$ & \\
\hline & E Compost mix & & 60 & 40 & & & & & & & \\
\hline & F Comp + Asub SMC & & 48 & 32 & & & & 20 & & & \\
\hline & G Comp + Abis SMC & & 48 & 32 & & & & & & 20 & \\
\hline & H Comp + past Asub SMC & & 48 & 32 & & & & & & & \\
\hline & A Compost mix & & 60 & 40 & & & & & & & \\
\hline Tomato & B Comp + Asub SMC & 5 & 51 & 34 & & & & 15 & & & no \\
\hline Combined $^{V}$ & A Plants + Mush. Comp. & & 50 & 20 & & & & $30^{\mathrm{VI}}$ & & & \\
\hline (cucumber & B Plants + past M.Comp. & & 50 & 20 & & & & & $30^{\mathrm{VI}}$ & & no \\
\hline and & C Plants + perlite & 3 & 50 & 20 & & & 30 & & & & no \\
\hline mushroom) & D no Plants + M. Comp. & & 50 & 20 & & & & $30^{\mathrm{VI}}$ & & & \\
\hline
\end{tabular}

I Agaricus bitorquis used instead of A. bisporus; ${ }^{\text {II }}$ mineralised SMC; ${ }^{\text {III }}$ spawn used instead of SMC; ${ }^{\text {IV }}$ pasteurised; ${ }^{\mathrm{V}}$ substrates not mixed (see Figure 1 for details). ${ }^{\mathrm{VI}}$ mushroom compost was used instead of SMC. 
Table 2. Chemical factors and plant available nutrient concentrations in some spent mushroom composts (SMCs, not pasteurised), mushroom composts still in cultivation, as well as other materials used as/in plant growing substrates. (A. sub = Agaricus subrufescens, $A$. bisp. $=A$. bisporus, FW $=$ fresh weight).

\begin{tabular}{|c|c|c|c|c|c|c|c|c|}
\hline & $\begin{array}{l}\text { A. sub. SMC } \\
\text { Exp } 2\end{array}$ & $\begin{array}{l}\text { A. sub. SMC } \\
\operatorname{Exp} 5\end{array}$ & $\begin{array}{l}\text { A. bisp. SMC } \\
\operatorname{Exp} 5\end{array}$ & $\begin{array}{l}\text { A. sub. } \\
\text { Mushroom Compost in }\end{array}$ & $\begin{array}{l}\text { A. bisp. } \\
\text { n Cultivation }\end{array}$ & Vermi-Compost & $\begin{array}{l}\text { Green Waste } \\
\text { Compost }\end{array}$ & $\begin{array}{l}\text { Commercial } \\
\text { Peat Substrate }\end{array}$ \\
\hline $\mathrm{pH}$ & 6.1 & 5.1 & 8.7 & 5.7 & 6.6 & 7.7 & 7 & 5.8 \\
\hline $\mathrm{EC}\left(\mathrm{mS} \mathrm{cm}^{-1}\right)$ & 3.8 & 2.6 & 23 & 3.35 & 4.1 & 9 & 2 & 1.3 \\
\hline Tot-N, mg kg-1 FW & & 4530 & 5330 & & & 6000 & 2000 & 3000 \\
\hline $\mathrm{NO}_{3}-\mathrm{N}, \mathrm{mg} \mathrm{L}^{-1}$ & 84 & 5 & 290 & & & 650 & 30 & 74 \\
\hline $\mathrm{NH}_{4}-\mathrm{N}, \mathrm{mg} \mathrm{L}^{-1}$ & & 5 & 3 & & & 1 & 5 & 50 \\
\hline $\mathrm{P}, \mathrm{mg} \mathrm{L}^{-1}$ & 75 & 110 & 100 & & & 150 & 120 & 40 \\
\hline $\mathrm{K}, \mathrm{mg} \mathrm{L}^{-1}$ & 377 & 4900 & 5500 & & & 1000 & 600 & 182 \\
\hline $\mathrm{Mg}, \mathrm{mg} \mathrm{L}^{-1}$ & 340 & 360 & 330 & & & 350 & 125 & 125 \\
\hline $\mathrm{S}, \mathrm{mg} \mathrm{L}^{-1}$ & 1640 & 1200 & 1600 & & & 200 & 50 & 52 \\
\hline $\mathrm{Ca}, \mathrm{mg} \mathrm{L}^{-1}$ & & 2000 & 2500 & & & 2000 & 900 & 971 \\
\hline $\mathrm{Mn}, \mathrm{mg} \mathrm{L}^{-1}$ & & 6.6 & 2.7 & & & 2.5 & 2 & 2.4 \\
\hline $\mathrm{B}, \mathrm{mg} \mathrm{L}^{-1}$ & & 0.88 & 0.69 & & & 1.6 & 1.5 & 0.2 \\
\hline $\mathrm{Fe}, \mathrm{mg} \mathrm{L}^{-1}$ & & 29 & 6.6 & & & 0.4 & 1 & 1.5 \\
\hline $\mathrm{Na}, \mathrm{mg} \mathrm{L}^{-1}$ & & 1200 & 1300 & & & 600 & 40 & 32 \\
\hline $\mathrm{Cl}, \mathrm{mg} \mathrm{L}^{-1}$ & & 2400 & 2400 & & & 700 & 30 & 11 \\
\hline Dry Matter & $35 \%$ & $25 \%$ & $30 \%$ & & & $45 \%$ & $42 \%$ & \\
\hline Ash content & $51 \%$ & $64 \%$ & $62 \%$ & & & $40 \%$ & $60 \%$ & \\
\hline
\end{tabular}




\subsection{Lettuce Cultivation}

Lettuce (Lactuca sativa L., var. Frillice Crispi, obtained from Norgro, NO) was sown directly into the substrates described. This was done within 10 days of mixing them. Unless specified otherwise, pots of $0.5 \mathrm{~L}$ were used. The greenhouse used for experiments 1-3 was a heated double polythene skin tunnel in Drammen (NO) with 400 W HPS growing lights (Gavita, NL). In experiments 4-5, a climate controlled experimental glasshouse with $400 \mathrm{~W}$ metal halide growing lamps (Osram, DE) at the University of Oslo (NO) was used. In both greenhouses, lamps were on from 06:00 to 21:00. The temperature was kept at $18-20^{\circ} \mathrm{C}$ during germination and at $18-23{ }^{\circ} \mathrm{C}$ during the growth period, with $\mathrm{RH}$ at $75-65 \%$ (night-day). The growth period was 8 weeks if not stated differently for the individual experiments. When organic fertigation was used, it was made with the liquid fraction of food waste digestate. The digestate was diluted with water until the desired EC (specified per experiment) was achieved. Lettuce heads (shoot) were cut at the basis and weighed. Dry weight, after drying at $60{ }^{\circ} \mathrm{C}$ for 48 hours, was also measured where stated.

\subsection{Lettuce Experiment 1}

SMC of A. subrufescens was added to a mix of GC and VC in increasing amounts ( $4-25 \%$ by volume; see Table 1 for details), to investigate its effect on substrate $\mathrm{pH}$ and lettuce growth. All treatments were fertigated with digestate liquid $\left(\mathrm{EC}=1.5 \mathrm{mS} \mathrm{cm}^{-1}\right)$. Substrate $\mathrm{pH}$ at the start and final lettuce head fresh weight were measured. The experiment was performed during April-May 2013.

\subsection{Lettuce Experiment 2}

The purpose of this experiment was to investigate the effects of adding SMC $(10 \% \mathrm{v} / \mathrm{v})$ to commercial fertilised peat substrate fertigated with mineral fertiliser. Fertigation started after two true leaves had emerged. The stock mineral solution was equal parts of Kristalon Brown and YaraLiva ${ }^{\mathrm{TM}}$ Calcinit (Yara, Oslo, Norway) diluted to $\mathrm{EC}=2.3 \mathrm{mS} \mathrm{cm} \mathrm{cm}^{-1}$. In addition, $\mathrm{SMC}$ and steam pasteurised SMC (at $60{ }^{\circ} \mathrm{C}$ for two hours) of $A$. subrufescens was compared to SMC of $A$. bitorquis. One treatment also received mineralised SMC, meaning the ash, which remained from the same volume of SMC as used in the other treatments, after treating at $550{ }^{\circ} \mathrm{C}$ for two hours. The purpose was to add similar minerals as with SMC, but without the organic compounds and microbes. In this experiment, smaller pots of $0.15 \mathrm{~L}$ were used. Substrate $\mathrm{pH}$ at the start and final lettuce head fresh and dry weights were measured. The experiment was performed during December 2013-February 2014.

\subsection{Lettuce Experiment 3}

The purpose of this experiment was to compare the effects of adding non-pasteurised and pasteurised SMC of $A$. subrufescens $\left(60^{\circ} \mathrm{C}\right.$ for two hours) to compost mix, and to investigate the effect of adding SMC to a compost mix with a higher vermicompost content. No fertigation was used. This meant that all nutrients available to the plant were present in the substrate mixes at the start. Lettuce head fresh weight was measured. The experiment was performed during November 2014-January 2015.

\subsection{Lettuce Experiment 4}

The effects of adding SMC of A. subrufescens and A. bisporus (non-pasteurised and pasteurised at $70^{\circ} \mathrm{C}$ ) to compost mix were again investigated. A commercial peat growing medium control was included. In addition, spawn (sterilised rye grain colonised by mycelium) of the two mushroom species was added ( $2 \%$ by volume) instead of SMC to the GC/VC compost mix. The purpose was to compare the effects on plant growth of spawn containing active mushroom mycelium with SMC containing passive mycelium. A further objective was to investigate the effect of digestate fertigation on plant growth. After one month, four pots from each treatment were fertigated with liquid digestate $(E C=2.5)$, the other four remained non-fertigated until harvest. Samples were taken of the mixed 
substrates at sowing and as combined samples at termination. Substrate $\mathrm{pH}, \mathrm{EC}$ and plant available nutrients, as well as lettuce head fresh and dry weights, were measured. The experiment was performed during November 2018-February 2019 and the growth period was 10 weeks.

\subsection{Lettuce Experiment 5}

This experiment investigated the plant growth effects of $A$. subrufescens SMC and A. bisporus SMC in non-fertigated compost mix and peat control (Table 1). The SMCs of the two species originated from the same mushroom compost batch, although the mushroom yield that had been obtained from it was higher for $A$. bisporus than for $A$. subrufescens. There were 20 replicate pots per treatment; 10 of the pots of each treatment were placed in the polytunnel greenhouse and the remaining 10 pots in the climate controlled glasshouse (conditions described above), to determine if there was an interaction between substrate treatments and growing conditions. Substrate $\mathrm{pH}, \mathrm{EC}$ and plant available nutrients, as well as lettuce head fresh and dry weights, were measured. The experiment was performed during May-June 2019 and was terminated 6 weeks after sowing (i.e., a shorter growth period than for the other lettuce experiments).

\subsection{Tomato Experiment}

This experiment investigated the effect of adding SMC of A. subrufescens to compost mix (proportions in Table 1) on the vegetative growth of tomato plants. Young plants of cherry tomato (Solanum lycopersicum L., var. Favorita F1), sown four weeks in advance in $1.5 \mathrm{~L}$ pots with GC + VC mix (60/40, v/v) were transplanted to $40 \mathrm{~L}$ growing bags filled with compost mix, with two plants per bag (treatment A). Six litres of compost mix were substituted with SMC in some of the bags (treatment B). The experiment was performed in a commercial tomato glasshouse without grow lights near Tønsberg (NO) during April-June 2019. During these weeks, the average conditions were: total daily insolation 1819 Joules $\mathrm{cm}^{-2}$, temperature $14-25^{\circ} \mathrm{C}$ (night-day) with $\mathrm{RH}$ at $89-70 \%$ (night-day). No fertigation was used during this period. The following growth parameters were recorded after five weeks of growth in the bags: shoot length, mean shoot length per week, stem diameter, leaf length $($ all in $\mathrm{cm})$, number of flowering trusses and number of flowers per truss. Simultaneously, substrate samples $(\mathrm{pH}$, EC and plant available nutrients) and leaf samples (plant sap analysis) were taken (combined within the treatments).

\subsection{Combined Experiment}

This experiment investigated the possibility of growing mushrooms and cucumbers in the same container. Therefore, mushroom compost, freshly grown with mycelium (not used for mushroom cropping in advance), was used instead of SMC. After full colonisation with mycelium, it was transferred to $40 \mathrm{~L}$ capacity plastic fish crates, $12 \mathrm{~L}$ per crate, forming a longitudinal ridge (Figure 1 ). GC (24 L) was then added to the crates. Two cucumber seedlings (Cucumis sativus, var. Allianz, Bejo Zaden) were planted in the GC in opposite corners of the crates, before topdressing with 4 L VC along the sides only. Topdressing with VC $(2 \mathrm{~L})$ was repeated twice through the trial. In treatment $\mathrm{B}$, pasteurised mushroom compost (at $60^{\circ} \mathrm{C}$ for two hours) substituted mushroom compost, as did perlite in treatment $C$. In treatment $D$, only mushrooms were grown and plants were omitted. All crates were sprinkled with water along the middle (over the ridge) in order to create a low EC zone for mushrooms to initiate directly in the GC (expected only in treatments A and D). The experiment was performed during February-June 2015 (a growth period of 19 weeks) in the tunnel greenhouse described above for the lettuce experiment and the growth conditions were the same as in that. Total fresh weights of cucumber fruits and mushrooms (stems trimmed to $50 \mathrm{~mm}$ length) were recorded. 
A

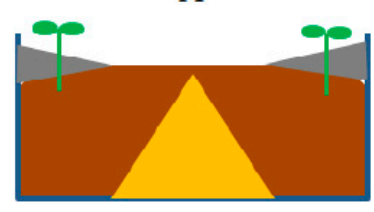

B

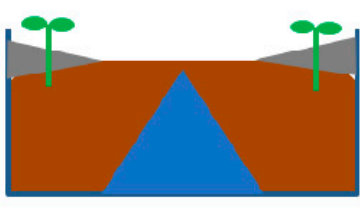

C

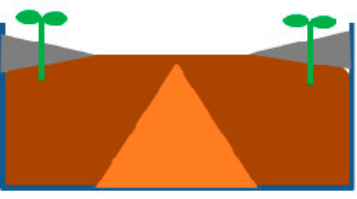

$\mathrm{D}$

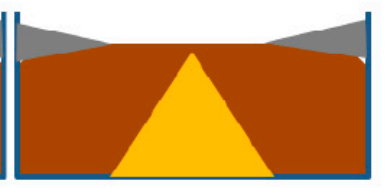

$\begin{array}{ll}\begin{array}{l}\text { Green waste } \\ \text { compost }\end{array} & \square \text { mycelium } \\ \text { masteurised } \\ \begin{array}{l}\text { mycelium } \\ \text { perlite }\end{array}\end{array}$

Figure 1. Design of the combined mushroom and cucumber experiment, showing how materials were arranged in the containers (cross section). Mycelium means here mushroom compost (not SMC). (A) Plants + mushroom compost; (B) Plants + pasteurised mushroom compost; (C) Plants + perlite; D: No Plants + mushroom compost. Volumes are given in Table 1 .

\subsection{Sampling and Analytical Methods}

Samples were taken from the fully mixed materials and/or substrates at the time of sowing by combining 10 sub-samples from the whole volume. Samples for plant available nutrients remaining at harvest were taken by including the whole pot volumes (excluding the larger coherent part of the root, which was shaken over the sample and discarded), combined and mixed within each treatment.

All analyses of plant available nutrients and chemical factors in substrates were performed by LMI AB, Helsingborg, SE, using a proprietary method based on a weak acetic acid extraction of the substrate (Modified Spurway). Chemical analysis of tomato leaf sap included tot-N (Dumas) and other elements (ICP-OES), which was performed by the same laboratory.

There were exceptions for lettuce experiments 1 and 2, and SMCs only listed with pH and EC values, where the following method was used: $25 \mathrm{~g}$ of fresh material was filled up with distilled water to a total of $100 \mathrm{~mL}$, keeping at $20{ }^{\circ} \mathrm{C}$ for half an hour, then using a Meterlab PHM210 pH meter (Radiometer Analytical, Villeurbanne Cedex, France). EC was measured in the same sample using an Orion STAR A325 (Fisher Scientific, Pittsburgh, US). EC in liquids for fertigation was measured at $20^{\circ} \mathrm{C}$ using the same device.

\subsection{Statistical Analysis}

Yield and shoot data were analysed as response variables and treatments (growing substrates) as categorical explanatory variables. Replicate growth containers (number given in Table 1 for each experiment) were organised in the greenhouse using a randomised block design. Boxplots and multi comparison tests (Tukey's HSD (honest significance difference)), as well as a Student's t-test for each measurement in the tomato experiment, were performed in R version 3.4.4 (2018-03-15, www.rproject.org). General data processing was made in Excel. In Lettuce experiment 4, the comparison test was performed on the non-fertigated and fertigated units separately. In Lettuce experiment 5 , the comparison test was performed on the peat-based and compost-based treatments separately.

\section{Results}

\subsection{Chemical Composition of Materials}

Chemical properties of SMC of A. subrufescens and A. bisporus are reported in Table 2. The $\mathrm{pH}$ of active and spent mushroom compost of $A$. subrufescens was lower than that of $A$. bisporus.

\subsection{Lettuce Experiment 1}

Inclusion of SMC of A. subrufescens had a significant positive effect on growth of lettuce in compost mix fertigated with digestate. However, increasing the amount above $4 \%$ by volume did not increase yield further. The substrate $\mathrm{pH}$ was lowered by increasing amounts of SMC (Figure 2). 


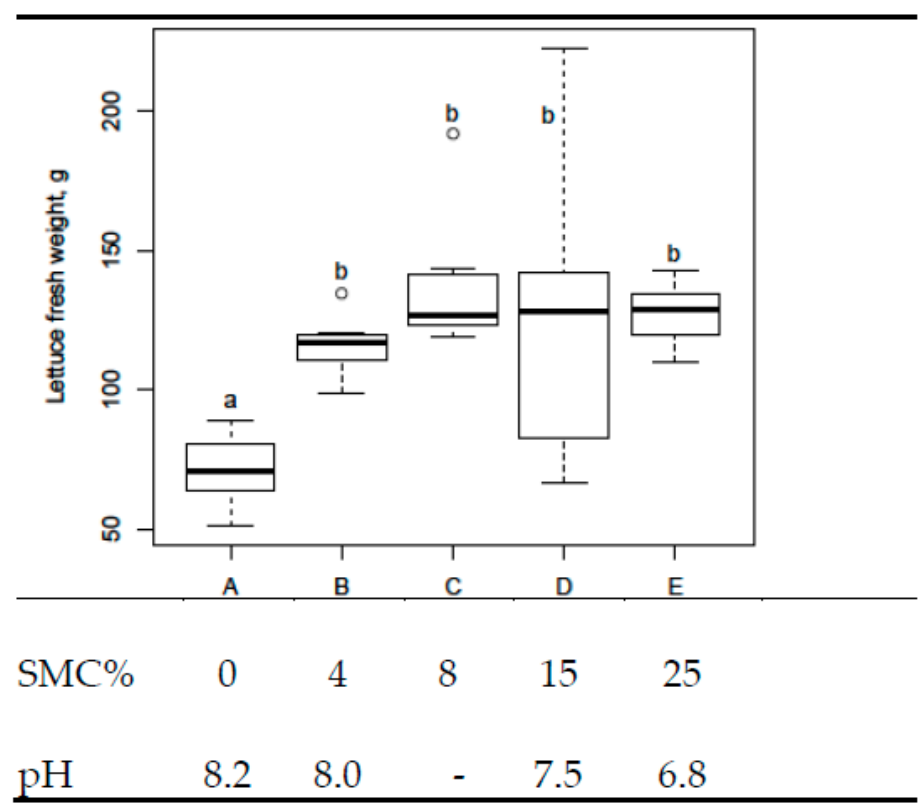

Figure 2. Fresh weight yield, proportion of SMC (by volume) added to the compost mix, and $\mathrm{pH}$ at sowing in Lettuce experiment 1 . Different lower case letters indicate significant differences between treatments according to a Tukey HSD test $(p<0.05)$. Spent mushroom compost (SMC) is A. subrufescens. Digestate fertigation used $\left(\mathrm{EC}=1.5 \mathrm{mS} \mathrm{cm}^{-1}\right)$. Details on the treatments are given in Table 1 .

\subsection{Lettuce Experiment 2}

When using commercial peat substrate and fertigation with mineral fertiliser $(E C=2.3)$, adding the SMC variants did not affect the yield of lettuce (average shoot fresh weight of $110 \mathrm{~g}$ ). Thus, no differences between the two Agaricus species, or between non-pasteurised, pasteurised or mineralised SMC were observed. The same conclusion was drawn using dry weight yield. The substrate $\mathrm{pH}$ was increased from 5.6 in the peat control to an average of 6.4 (standard deviation $=0.3$ ) by the additions of SMC (no figure or table included).

\subsection{Lettuce Experiment 3}

There was a significant effect of substituting a part of the unfertilised peat and perlite with SMC of $A$. subrufescens in compost substrate, when it contained a high percentage of vermicompost (see Figure 3, treatments $\mathrm{E}$ and F). These composts produced a higher yield than treatments containing less vermicompost (treatments $C$ and $D$ ). For these, there was no difference between live and pasteurised SMC. Adding SMC to fertilised peat did not have a significant effect on yield (treatments A and B).

\subsection{Lettuce Experiment 4}

The chemical properties of the mixed substrates are presented in Table 3. The average fresh weight of the non-fertigated and fertigated lettuce heads was $119 \mathrm{~g}$ and $202 \mathrm{~g}$, respectively (this difference was significant, $p<0.01$ ). Among the fertigated, there were no significant differences between the treatments. In the non-fertigated treatments, the yield was more than doubled when $20 \%$ of the commercial peat substrate was substituted with SMC (compare treatments A and B, Figure 4, where only the non-fertigated are included). There were no other significant differences. The dry weight yield data led to the same conclusions and are therefore not presented. 

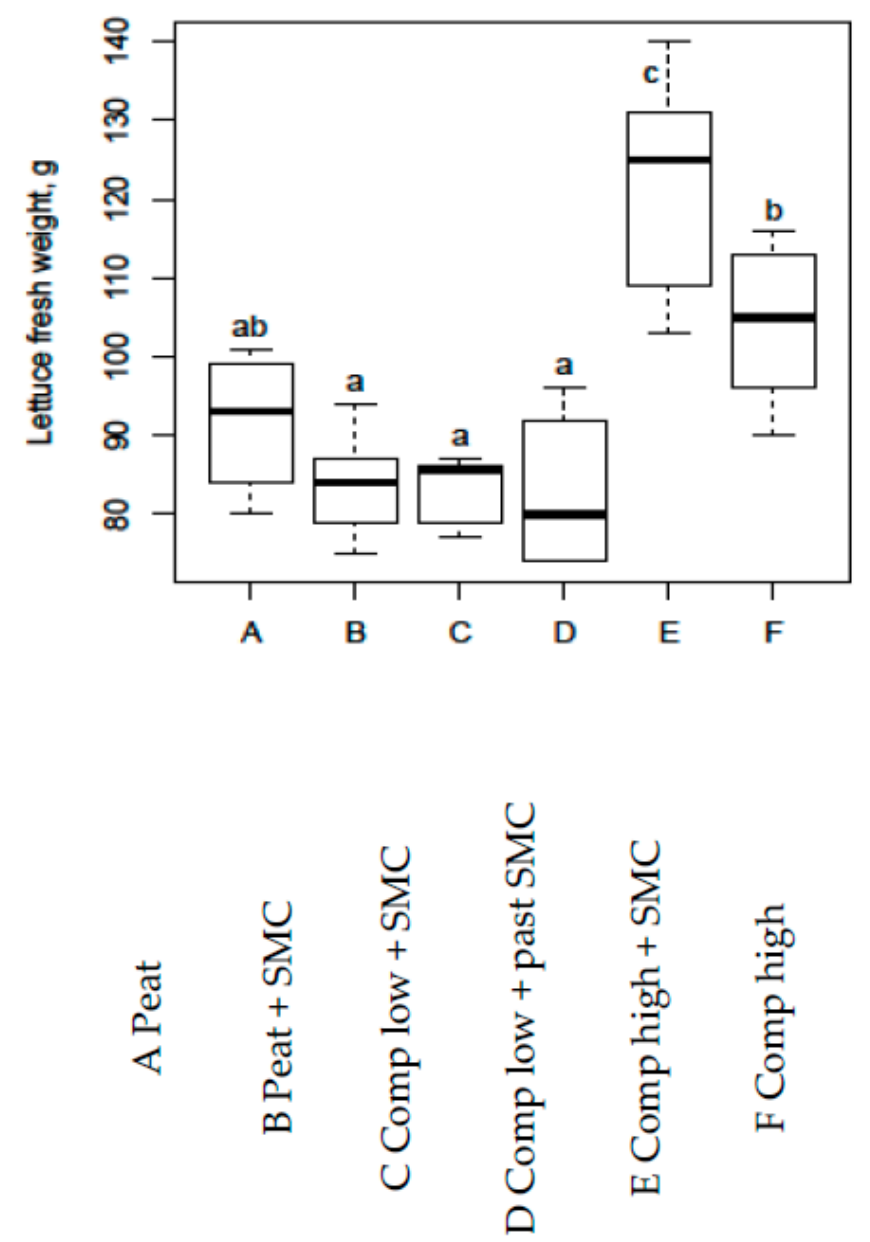

Figure 3. Fresh weight yield in Lettuce experiment 3. Different lower case letters indicate significant differences between treatments according to a Tukey HSD test $(p<0.05)$. SMC is A. subrufescens. No fertigation used. Details on the treatments are given in Table 1.

Table 3. Chemical factors and plant available nutrient content of substrates before and after cultivation in Lettuce experiment 4 (Treatments A-H are detailed in Table 1 and indicated in Figure 4).

\begin{tabular}{|c|c|c|c|c|c|c|c|c|}
\hline & A & B & $\mathrm{C}$ & D & $\mathrm{E}$ & $\mathbf{F}$ & G & $\mathbf{H}$ \\
\hline \multicolumn{9}{|l|}{ At sowing: } \\
\hline $\mathrm{pH}$ & 7.0 & 6.8 & 8.2 & 8.2 & 8.0 & 8.5 & 8.4 & 8.2 \\
\hline $\mathrm{EC}, \mathrm{mS} \mathrm{cm}^{-1}$ & 2.4 & 9.1 & 4.3 & 12.5 & 13 & 4.3 & 5.4 & 5.5 \\
\hline Tot-N, mg kg-1 FW & 2800 & 5520 & 7620 & 7630 & 8580 & 6680 & 7460 & 6950 \\
\hline $\min . \mathrm{N}^{\mathrm{i}}, \mathrm{mg} \mathrm{L}^{-1}$ & 135 & 205 & 119 & 310 & 260 & 43,5 & 59 & 93 \\
\hline $\mathrm{P}, \mathrm{mg} \mathrm{L}^{-1}$ & 70 & 80 & 175 & 155 & 160 & 165 & 145 & 150 \\
\hline $\mathrm{K}, \mathrm{mg} \mathrm{L}^{-1}$ & 250 & 955 & 730 & 1800 & 1550 & 785 & 850 & 795 \\
\hline $\mathrm{S}, \mathrm{mg} \mathrm{L}^{-1}$ & 77 & 650 & 120 & 730 & 610 & 150 & 330 & 280 \\
\hline $\mathrm{Fe}, \mathrm{mg} \mathrm{L}^{-1}$ & 1.1 & 1.7 & 0.53 & 1.4 & 1.1 & 0.62 & 0.55 & 0.56 \\
\hline $\mathrm{Na}, \mathrm{mg} \mathrm{L}^{-1}$ & 38 & 230 & 270 & 570 & 540 & 290 & 320 & 300 \\
\hline $\mathrm{Cl}, \mathrm{mg} \mathrm{L}^{-1}$ & 10 & 410 & 250 & 900 & 840 & 280 & 310 & 250 \\
\hline \multicolumn{9}{|c|}{ At end of experiment: } \\
\hline $\min . \mathrm{N}^{\mathrm{i}}, \mathrm{mg} \mathrm{L}^{-1}(-/+$ fert $)$ & $2 / 52$ & $7 / 61$ & $10 / 30$ & $16 / 89$ & $50 / 97$ & $16 / 44$ & $2 / 35$ & $5 / 55$ \\
\hline $\mathrm{P}, \mathrm{mg} \mathrm{L}^{-1}(-/+$ fert $)$ & $31 / 35$ & $78 / 81$ & $160 / 150$ & $150 / 170$ & $160 / 180$ & $150 / 170$ & $160 / 150$ & $160 / 170$ \\
\hline $\mathrm{K}, \mathrm{mg} \mathrm{L}^{-1}(-/+$ fert $)$ & $24 / 43$ & $39 / 50$ & $310 / 75$ & $390 / 330$ & $710 / 300$ & $340 / 110$ & $190 / 68$ & $120 / 66$ \\
\hline
\end{tabular}




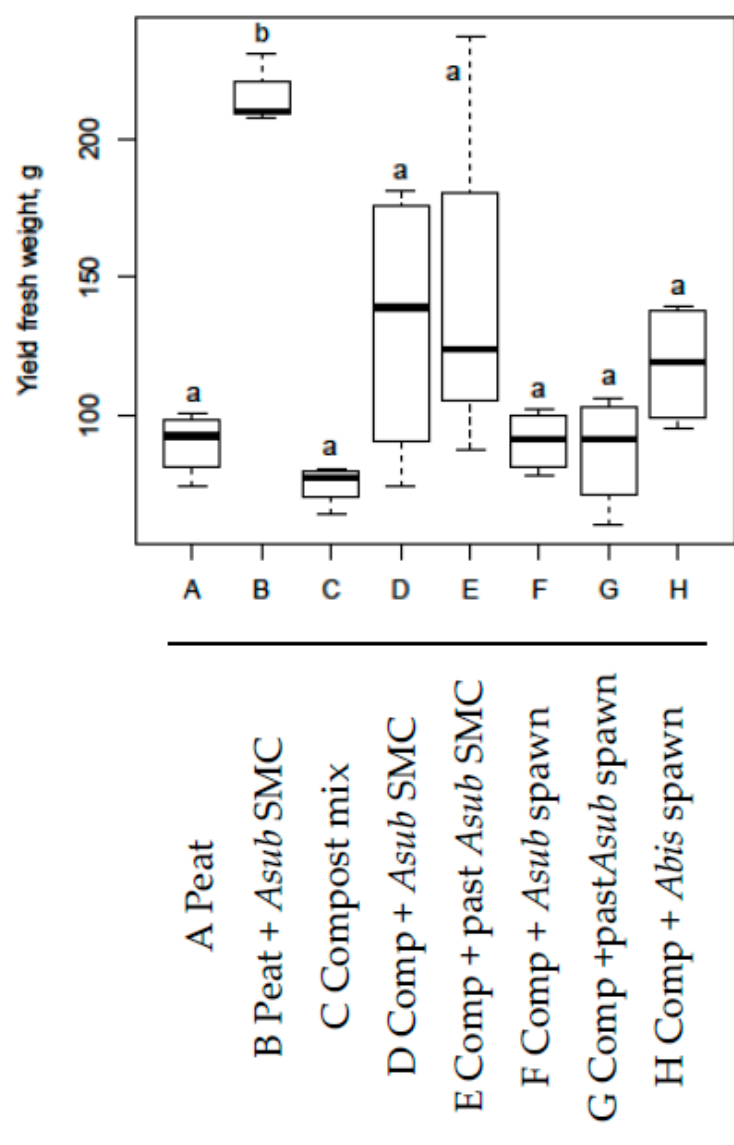

Figure 4. Fresh weight yield of the non-fertigated plants in Lettuce experiment 4. Different lower case letters indicate significant differences between treatments according to a Tukey HSD test $(p<0.05)$. Details on the treatments are given in Table 1.

The addition of SMC did not impact substrate $\mathrm{pH}$, but increased the $\mathrm{EC}, \mathrm{K}, \mathrm{S}, \mathrm{Na}$ and $\mathrm{Cl}$ contents of both peat and compost mixes. Addition of spawn reduced available N (Table 3).

\subsection{Lettuce Experiment 5}

Addition of SMC reduced germination in both commercial peat and compost mix substrates, but not when the SMC was pasteurised (Table 4). There was a significant difference between the two greenhouses. Yield was higher in the polytunnel than in the experimental glasshouse $(p=0.02)$. However, there was no interaction with substrate on yield ( $p$-values $>0.43$ ). Therefore, the data for the two environments were combined. The main yield differences between treatments in this experiment were that peat-based substrates performed better than compost-based substrates (the mean fresh weights were 29 and $17 \mathrm{~g}$ on peat and compost, respectively, $p<0.01$ ). The differences among the peat substrates and among the compost substrates were then tested separately. This showed there was no significant effect of adding SMC to the peat treatments (Figure 5). Among the compost treatments, the one with added pasteurised SMC $(\mathrm{H})$ yielded significantly better than the one without SMC $(\mathrm{E})$, while the two with non-pasteurised (F and $G$ ) were not significantly different to any of these two. The dry weight yield data led to the same conclusions, and are therefore not presented. 
Table 4. Germination percentage, chemical properties and plant available nutrient content at sowing in Lettuce experiment 5. (FW $=$ fresh weight. Treatments A-H are detailed in Table 1 and indicated in Figure 5).

\begin{tabular}{|c|c|c|c|c|c|c|c|c|}
\hline & $\mathbf{A}$ & B & C & D & E & $\mathbf{F}$ & G & $\mathbf{H}$ \\
\hline Germination $\%$ & 85 & 60 & 30 & 90 & 70 & 60 & 60 & 75 \\
\hline $\mathrm{pH}$ & 5.4 & 6 & 5.8 & 6 & 7.8 & 8.5 & 7.9 & 8 \\
\hline $\mathrm{EC}, \mathrm{mS} \mathrm{cm}^{-1}$ & 3.2 & 6.7 & 6.8 & 5.2 & 3.9 & 6.5 & 9.2 & 11 \\
\hline Tot-N, mg kg-1 FW & 3210 & 3910 & 4360 & 2720 & 6590 & 5440 & 6810 & 5950 \\
\hline $\min . \mathrm{N}^{\mathrm{i}}, \mathrm{mg} \mathrm{L}^{-1}$ & 250 & 160 & 230 & 180 & 55 & 35 & 150 & 140 \\
\hline $\mathrm{P}, \mathrm{mg} \mathrm{L}^{-1}$ & 110 & 71 & 72 & 79 & 140 & 120 & 150 & 140 \\
\hline $\mathrm{K}, \mathrm{mg} \mathrm{L}^{-1}$ & 300 & 940 & 980 & 820 & 950 & 1800 & 1800 & 2100 \\
\hline $\mathrm{S}, \mathrm{mg} \mathrm{L}^{-1}$ & 140 & 320 & 320 & 320 & 180 & 430 & 420 & 520 \\
\hline $\mathrm{Na}, \mathrm{mg} \mathrm{L}^{-1}$ & 40 & 210 & 220 & 180 & 170 & 370 & 370 & 450 \\
\hline $\mathrm{Cl}, \mathrm{mg} \mathrm{L}^{-1}$ & 2 & 480 & 470 & 370 & 180 & 770 & 770 & 1000 \\
\hline
\end{tabular}

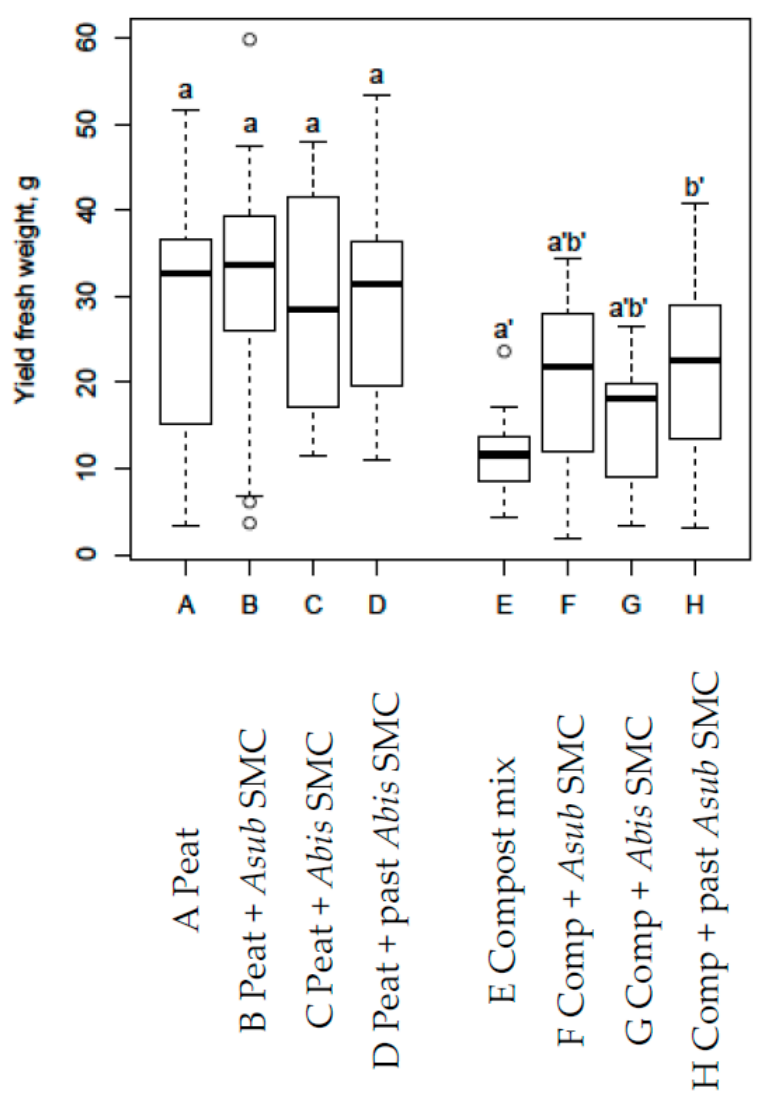

Figure 5. Fresh weight yield in Lettuce experiment 5. No fertigation used. Different lower case letters indicate significant differences between treatments according to a Tukey HSD test $(p<0.05)$. Peat treatments (A-D) and compost treatments (E-F) were statistically tested separately. Details on the treatments are given in Table 1.

Compost substrates had higher $\mathrm{pH}, \mathrm{EC}$ and $\mathrm{Na}$ and $\mathrm{Cl}$ contents than peat substrates (except treatment $\mathrm{E}$, unamended compost mix, which had a lower $\mathrm{EC}$ and salt content than peat substrates with SMC (B, C and D)). Compost treatments also had lower available nitrogen.

\subsection{Tomato Experiment}

Substituting $15 \%$ by volume of the compost mix with SMC of $A$. subrufescens had a positive effect on most vegetative growth measurements of tomato plants. Flowers per truss were not different, while 
all other measurements were significantly improved by adding SMC (Figure 6). At this point (after five weeks of growth in the bags) the substrate with added SMC contained more available N, S and Fe. The plant leaf analysis also showed slightly higher values for these elements (Table 5) when SMC was added to the substrate. The plants without SMC showed general signs of $\mathrm{N}$ deficiency.

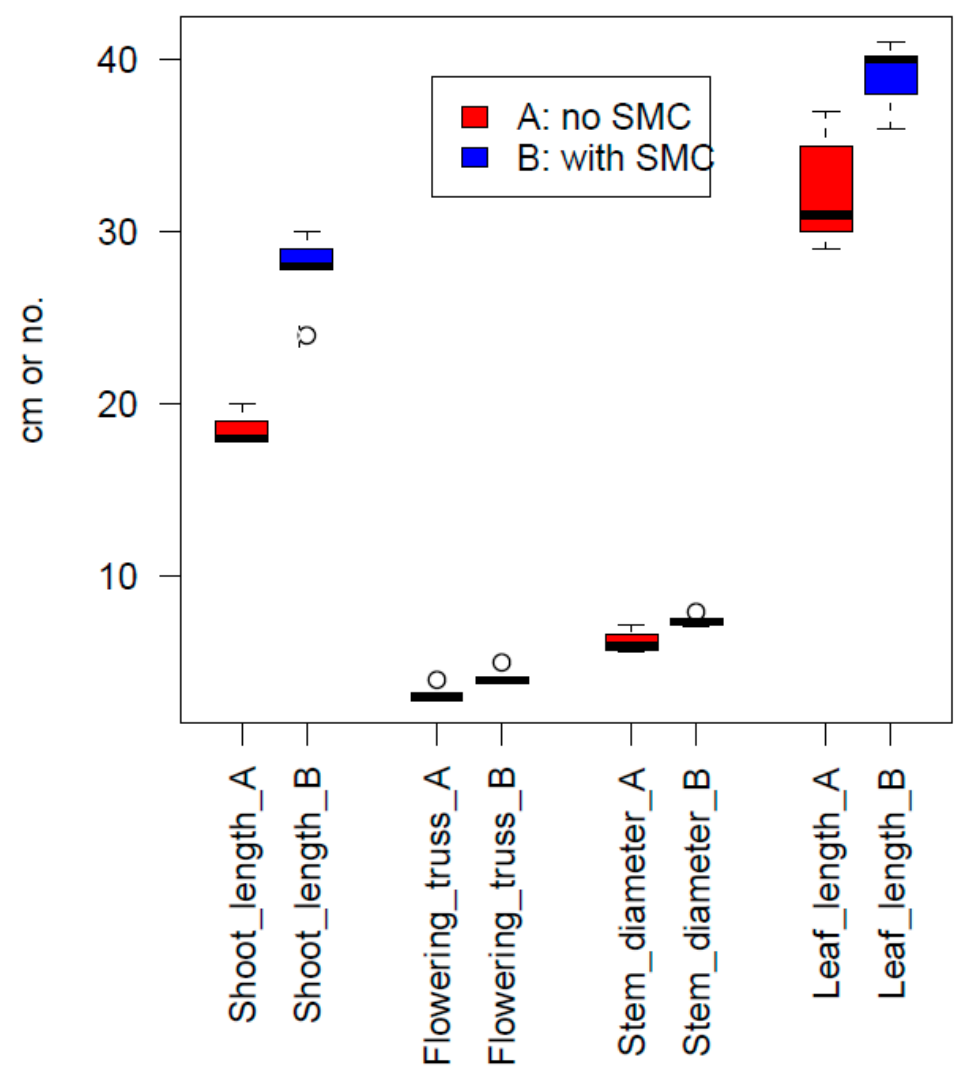

Figure 6. Growth measurements of tomato plants after five weeks of growth in the bags. All measurements shown were significantly different for the two treatments $(p<0.05$, Student's t-test performed for each measurement). SMC is A. subrufescens.

Table 5. Chemical analysis of tomato substrate and plant leaves in after five weeks of growth in compost mix without and with SMC. DM = dry matter. A: Compost mix without SMC. B: Compost mix with SMC.

\begin{tabular}{ccc}
\hline & A & B \\
\hline \multicolumn{2}{c}{ Substrate (Plant Available Nutrients) } \\
\hline $\mathrm{pH}$ & 8.4 & 8.4 \\
$\mathrm{EC}, \mathrm{mS} \mathrm{cm}^{-1}$ & 2.2 & 5.3 \\
$\mathrm{NO}-\mathrm{N}+\mathrm{NH}_{-}-\mathrm{N}^{-1} \mathrm{mg} \mathrm{L}^{-1}$ & 19 & 40 \\
$\mathrm{P}, \mathrm{mg} \mathrm{L}^{-1}$ & 130 & 86 \\
$\mathrm{~K}, \mathrm{mg} \mathrm{L}^{-1}$ & 700 & 1000 \\
$\mathrm{~S}, \mathrm{mg} \mathrm{L}^{-1}$ & 71 & 290 \\
$\mathrm{Fe}, \mathrm{mg} \mathrm{L}^{-1}$ & 1.0 & 5.4 \\
\multicolumn{1}{c}{ Plants (leaf sap analysis) } & \\
Tot-N, $\mathrm{mg}^{-\mathrm{kg}} \mathrm{DM}$ & 17800 & 23900 \\
$\mathrm{P}, \mathrm{mg}^{-\mathrm{kg}} \mathrm{DM}$ & 4230 & 3330 \\
$\mathrm{~K}, \mathrm{mg}^{-\mathrm{kg}} \mathrm{DM}$ & 33000 & 36000 \\
$\mathrm{~S}, \mathrm{mg}^{-\mathrm{kg}} \mathrm{DM}$ & 10000 & 12000 \\
$\mathrm{Fe}, \mathrm{mg}^{-\mathrm{kg}} \mathrm{DM}$ & 55 & 64 \\
\hline
\end{tabular}




\subsection{Combined Experiment}

Mushrooms and plants were grown together in the same container (Figure 7). However, there was a significantly higher cucumber yield when the mycelium was inactivated by pasteurisation (B) than in the live mycelium (A) and perlite (C) treatments. Mushrooms fruited in one crate despite pasteurisation (B).

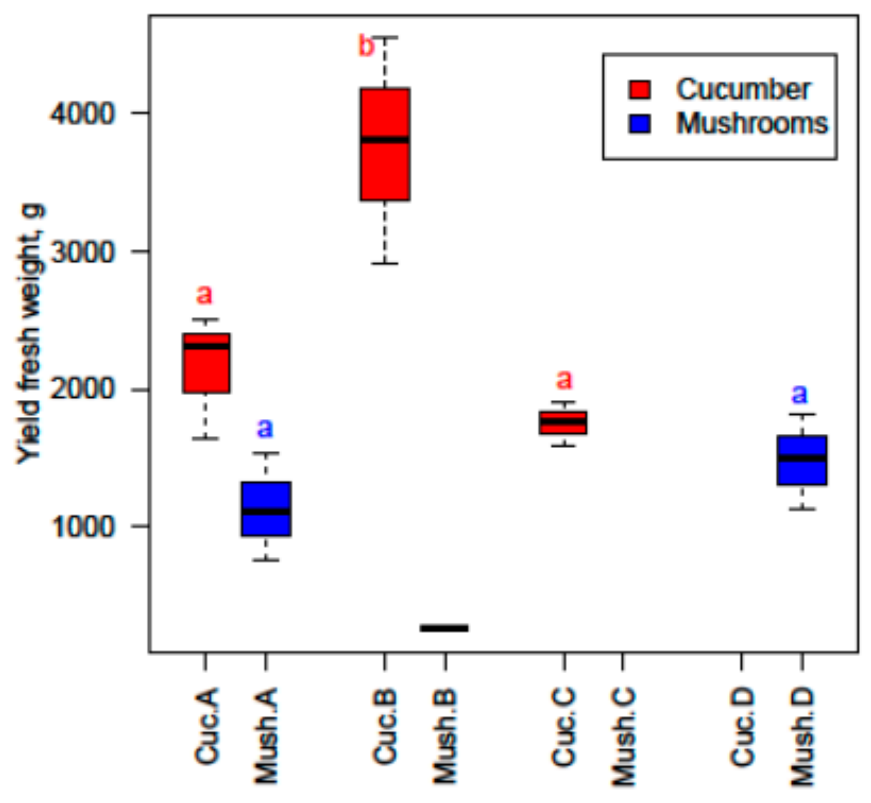

Figure 7. Fresh yield of cucumbers and A. subrufescens mushrooms. Within each species, different lower case letters indicate significant differences between the treatments according to a Tukey HSD test $(p<0.05)$. No fertigation was used. Details of treatments are given in Table 1 and Figure 1.

\section{Discussion}

Significant positive effects on greenhouse plant crop growth from adding SMC reported by others can be categorised as (1) Substrate substitution for seedling production, no mineral fertiliser added $[14,19,20,23,24]$. (2) Substrate substitution for plant production, with additional mineral fertiliser added $[11,16,25,26]$. (3) Addition to natural soils as an organic amendment/biofertiliser, no mineral fertiliser added $[9,17,18,27,28]$. (4) Addition to natural soils as an organic amendment, with additional mineral fertiliser added $[19,29]$. Sustainable utilisation of the SMC is usually a primary motivation for the research. In cases 1 and 2, finding cheap substitutes for commercial substrates or peat is also an important factor. For 3 and 4 , there is the additional prospect of improving the general structure, fertility and available nutrients of the soil. Stimulated growth was a secondary positive consequence. 
For the works under 1 and 2 above, there are no clear explanations for the improved growth provided. An exception is Young et al. [26], who suggested that SMC had the advantage of a nutrient release over time because SMC decomposition supplemented the basic fertiliser solution. Most authors only emphasise that the substrates containing SMC are within acceptable levels with regard to physical and chemical parameters. However, biological factors may play an important role in such soil-less systems (as suggested by Lopes et al [20]. and Ahmad et al. [30]).

For the works listed under 3 and 4 above (greenhouse studies using in situ or natural soil) the improved plant growth was commonly explained by the positive effect SMC had on soil properties, such as organic matter, water holding capacity, density, available nutrients etc. Where informed, the original soil used had a very low organic matter, salt and nutrient contents compared to the SMC applied.

There is consensus that a major challenge with utilising fresh untreated SMC is its high salt content. Therefore, in most studies, the SMC used is weathered passively over an extended period, or actively leached before use. Seedlings are especially sensitive to high salt levels, whereas later stage plants can tolerate moderate levels. For example, Chong et al. [25] reported that the control bark medium (for containerised woody species) had an EC of 0.4, while the unweathered SMC, weathered SMC and leached SMC had ECs of 8.7, 5.5 and $0.8 \mathrm{mS} \mathrm{cm}^{-1}$, respectively. They also refer to an optimum EC of 2.1-3.5 mS cm${ }^{-1}$. For seedlings, Zhang et al. [14] found that a substrate consisting of SMC (of Flammulina, composted and pasteurised) with perlite or vermiculite supported better tomato and cucumber seedlings than the peat control. The control, SMC and successful mixes had ECs of 0.9, 2.5 and 1.4-1.5 mS cm${ }^{-1}$, respectively. All nutrient ions contribute to the EC. However, $\mathrm{Na}^{+}$and $\mathrm{Cl}^{-}$ are most often the problematic ones present at much higher concentrations than is optimal for both seedlings and later stage plants. In addition, $\mathrm{K}^{+}$is high in $\mathrm{SMC}$, and excessive levels may lead to imbalances or "antagonism" between $\mathrm{K}^{+}, \mathrm{Ca}^{2+}$ and $\mathrm{Mg}^{2+}$ ions [28]. However, $\mathrm{K}^{+}$is also one of the ions that is most easily leached $[9,25]$.

The EC of the basic compost substrates tested in the present study with SMC was high compared to what is generally recommended in conventional horticulture. The high salt content of the vermicompost based on food waste digestate was the source of most of the salts (Table 2). A high inclusion of vermicompost is still beneficial when combined with green waste compost [31], as was seen in the present study, where the compost mix (without SMC) often gave equal or better yield of lettuce than the control. However, adding $\mathrm{SMC}$ to the compost mixes added additional $\mathrm{K}^{+}, \mathrm{SO}_{4}{ }^{2-}, \mathrm{Na}^{+}$and $\mathrm{Cl}^{-}$on top of already high levels provided by the vermicompost.

In Stoknes et al. [32], the growing mycelium of A. subrufescens reduced the $\mathrm{pH}$ of the digestate based mushroom compost from 8.2 at inoculation to 5.1 at the time of harvesting the first flush of mushrooms. The $\mathrm{pH}$ values towards the end of cultivation in the present study (Table 2) are similar. The reduced $\mathrm{pH}$ is probably due to the high density of oxalic acid crystals accumulating on the mushroom mycelium during growth [33]. A pH reduction from mixing in SMC to high $\mathrm{pH}$ compost substrates would be beneficial. This was measured in Lettuce experiment 1 . However, it was not observed (or not measured) in the other experiments. Therefore, this should be followed up with a more thorough investigation of $\mathrm{pH}$ of SMCs and mixes with compost.

Saprotrophic macrofungi (decayers producing visible mushrooms) and plants interact closely in natural ecosystems. This can be directly observed when grassland fungi, such as Agaricus species, form "fairy rings" (Figure 8), where the mycelial progress often leaves behind a dark green belt of lush vegetation [34,35]. A lab experiment with the saprotrophic grassland species Saproamanita thiersii showed that growth of several grasses was stimulated by its inoculation into sterilised sandy soil [36]. The effect of these fungi in natural soils may be indirect. An experiment with inoculation of Agaricus bisporus into mineral soil showed enhanced carbon mineralization because of mycelium-enhanced water transport, which in turn stimulated other microbes [37], which might again stimulate plant growth. The field mushroom (A. campestris) is a ring former in lawns and meadows, but resists cultivation. It requires the presence of grass and may have some association with grass roots [38,39]. 
On the other hand, the horse mushroom (A. arvenis) forms rings and can be grown commercially [40,41]. Neither Agaricus bisporus nor A. bitorquis are ring formers, and in the wild grow in decaying leaf litter. This probably also holds for A. subrufescens [38]. The positive effects on plant growth seen in this study were mostly connected to pasteurised SMC in the lettuce experiments, and clearly to inactivated mycelium in the combined experiment. It is therefore unlikely that there was a "ring-like" interaction between fungus and plant in these trials. Even though Ribas et al. [18] suggested that fresh, non-pasteurised SMC might have an advantage over more degraded or pasteurised SMC (having a beneficial microbiology), the present study did not support this.

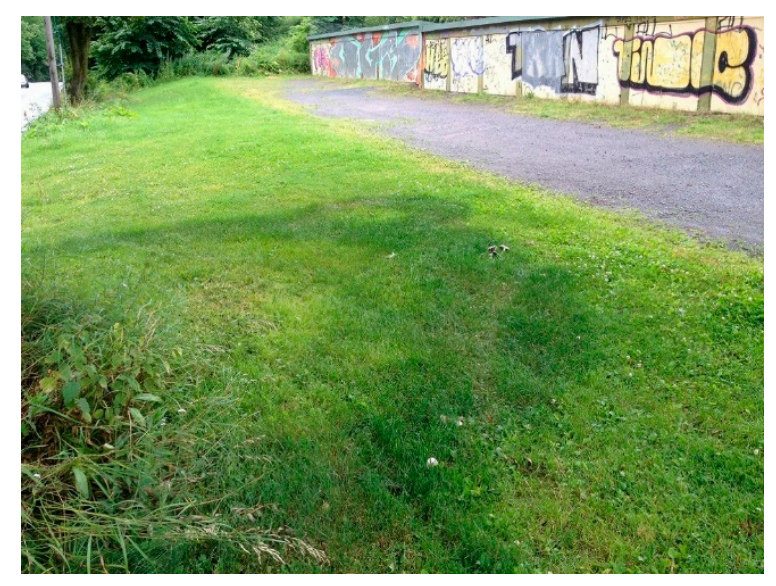

Figure 8. "Fairy ring" of Agaricus sp. in Oslo, Norway.

In several experiments when full fertigation was not used, adding SMC to compost substrates significantly increased available nutrients, especially $\mathrm{N}$, but also available $\mathrm{K}$ and $\mathrm{S}$. This ameliorated the negative effects of high $\mathrm{pH}$ and EC and improved plant growth, even when the EC increased to levels far above "optimal". For most vegetables, this is an $\mathrm{EC}<2.5 \mathrm{mS} \mathrm{cm}^{-1}$ (at $\mathrm{pH}$ 6), as emphasized in the SMC-literature above $[9,11,13,14,16,28]$. This was the case for SMC amended compost in Lettuce experiments 3 and 5 . When the addition was too high, such as for treatment $\mathrm{E}$ in Lettuce experiment 1 , this probably resulted in excessive levels of $\mathrm{K}^{+}, \mathrm{Na}^{+}$and $\mathrm{Cl}^{-}$, which off-set the positive effects.

The importance of pasteurisation, which is a common practice in the mushroom industry ("cook-out" of the growing room), should be investigated further. In Lettuce experiment 5 , the reduced germination was only observed with non-pasteurised SMC. Further work is needed to determine whether the observed effect of SMC pasteurisation on lettuce seed germination was due to biological or abiotic factors or due to SMC variation from batch to batch.

This work has concentrated on crop yield and above ground plant weight. Further work is needed to determine whether the growing medium treatments affect root growth. In addition, the effect of $\mathrm{SMC}$ on $\mathrm{pH}$ in compost substrates should be investigated further, especially if Agaricus subrufescens can be more effective than the more commonly cultivated A. bisporus.

\section{Conclusions}

A significantly better plant growth in treatments with added SMC of $A$. subrufescens was observed in the following situations:

- Lettuce experiment 1 (digestate fertigation used, $\mathrm{EC}=1.5 \mathrm{mS} \mathrm{cm}^{-1}$ ).

- Lettuce experiment 3 , in nutrient rich compost mix when $10 \%$ of the non-fertilised peat and perlite was substituted with SMC (no fertigation used).

- Lettuce experiment 4 , in the commercial peat substrate when $20 \%$ of the volume was substituted with SMC and no fertigation was used.

- Lettuce experiment 5 , in compost mix with added pasteurised SMC. 
- Tomato experiment, in compost mix with added SMC (15\% by volume, no fertigation used).

- Cucumber combined experiment, with pasteurised mushroom compost (no fertigation used).

No effect on plant growth was observed:

- From increasing the amount of SMC further in Lettuce experiment 1.

- From adding SMC of any state to fertilised peat in Lettuce experiment 2 (mineral fertigation used, $\mathrm{EC}=2.3 \mathrm{mS} \mathrm{cm}^{-1}$ ).

- From adding SMC of any state in Lettuce experiment 4 to the non-fertigated composts, or to any fertigated substrates.

- When pots were fertigated with digestate at $\mathrm{EC}=2.5 \mathrm{mS} \mathrm{cm}^{-1}$ in Lettuce experiment 4 .

- From adding spawn in Lettuce experiment 4.

- From adding SMC of any state to peat substrates or from adding non-pasteurised SMC to compost mix in Lettuce experiment 5 (no fertigation used).

Addition of non-pasteurised SMC had a negative effect on germination in Lettuce experiment 5 (but not when pasteurised). Apart from this, no negative effects were found from substituting peat or compost mix with SMC in the experiments.

Thus, addition of pasteurised mushroom compost of Agaricus subrufescens to green waste compost and vermicompost resulted in improved growth of lettuce, tomato and cucumber. This was the case in several situations within six out of seven independent trials, but not when full fertigation with mineral or organic (liquid digestate) solution was used. No negative effects were observed, apart from a reduction of germination in one of the experiments when the SMC was not pasteurised.

Combined cultivation of $A$. subrufescens mushrooms and cucumbers was not successful in terms of cucumber productivity, and showed that living mycelium did not release plant available nutrients.

The present study demonstrates a method for offsetting the effects of high $\mathrm{pH}$ and EC, as well as limited nutrient supply (and nutrient immobilisation) of peat-free, compost-based growing media on vegetable plant growth, by using pasteurised Agaricus mycelium colonised compost.

Author Contributions: Conceptualization, K.S., E.W. and A.J.; methodology, K.S., E.W. and A.J.; validation, K.S.; formal analysis, K.S.; investigation, E.W. and A.J.; resources, E.W. and A.J.; data curation, K.S.; writing-original draft preparation, K.S.; writing-review and editing, K.S., R.N. and E.W.; visualization, K.S.; supervision, K.S.; project administration, K.S.; funding acquisition, K.S., please turn to the CRediT taxonomy for the term explanation.

Funding: This research was funded by Project no. ECO/11/304388 from the EACI acting according to the powers delegated by the European Commission within the framework of CIP Eco-innovation; Lindum AS, a waste company owned by the Municipality of Drammen City, Norway; Project no. 272065 at Regionale forskningsfond Oslofjordfondet, Norway.

Conflicts of Interest: The authors declare no conflict of interest. The funders had no role in the design of the study; in the collection, analyses or interpretation of data; in the writing of the manuscript, or in the decision to publish the results.

\section{References}

1. Putra, P.A.; Yuliando, H. Soilless culture system to support water use efficiency and product quality: a review. Agric. Agric. Sci. Proced. 2015, 3, 283-288. [CrossRef]

2. Barrett, G.E.; Alexander, P.D.; Robinson, J.S.; Bragg, N.C. Achieving environmentally sustainable growing media for soilless plant cultivation systems-A review. Sci. Hortic. 2016, 212, 220-234. [CrossRef]

3. Gao, J.; Holden, J.; Kirkby, M. The impact of land-cover change on flood peaks in peatland basins. Water Resour. Res. 2016, 52, 3477-3492. [CrossRef]

4. Heikkinen, K.; Ihme, R.; Osma, A.M.; Hartikainen, H. Phosphate removal by peat from peat mining drainage water during overland flow wetland treatment. J. Environ. Qual. 1995, 24, 597-602. [CrossRef]

5. Fraixedas, S.; Lindén, A.; Meller, K.; Lindström, Å.; Keišs, O.; Kålås, J.A.; Husby, M.; Leivits, A.; Leivits, M.; Lehikoinen, A. Substantial decline of Northern European peatland bird populations: Consequences of drainage. Biol. Conserv. 2017, 214, 223-232. [CrossRef] 
6. Zheng, Y.; Huber, J.; Ping, Z.; Dixon, M. Searching for recyclable or biodegradable growing media. Acta Hortic. 2009, 819, 435-442. [CrossRef]

7. Carlile, W.R. The use of composted materials in growing media. Acta Hortic. 2008, 779, 321-328. [CrossRef]

8. Raviv, M. Composts in growing media: What's new and what's next? Acta Hortic. 2013, 982, 39-52. [CrossRef]

9. Gonani, Z.; Riahi, H.; Sharifi, K. Impact of using leached spent mushroom compost as a partial growing media for horticultural plants. J. Plant Nutr. 2011, 34, 337-344. [CrossRef]

10. Sendi, H.; Mohamed, M.T.M.; Anwar, M.P.; Saud, H.M. Spent mushroom waste as a media replacement for peat moss in kai-lan (Brassica oleracea var. Alboglabra) production. Sci. World J. 2013, 2013, 8. [CrossRef]

11. Topcuoglu, B. The usability of sewage sludge municipal solid waste compost and spent mushroom compost as growing media on the growth of Euphorbia pulcherrima. IPCBEE 2011, 24, 386-392.

12. Medina, E.; Paredes, C.; Pérez-Murcia, M.D.; Bustamante, M.A.; Moral, R. Spent mushroom substrates as component of growing media for germination and growth of horticultural plants. Bioresour. Technol. 2009, 100, 4227-4232. [CrossRef] [PubMed]

13. Wever, G.; van der Burg, A.M.M.; Straatsma, G. Potential of adapted mushroom compost as a growing medium in horticulture. Acta Hortic. 2005, 697, 171-177. [CrossRef]

14. Zhang, R.-H.; Duan, Z.-Q.; Li, Z.-G. Use of spent mushroom substrate as growing media for tomato and cucumber seedlings. Pedosphere 2012, 22, 333-342. [CrossRef]

15. Oancea, F.; Răut, I.; Șesan, T.E.; Doni, M.; Popescu, M.; Jecu, M.L. Enhancement of biostimulant activity of spent Pleurotus substrate for seedling production. Acta Hortic. 2017, 1164, 55-62. [CrossRef]

16. Chong, C.; Cline, R.A.; Rinker, D. Bark- and peat- amended spent mushroom compost for containerized culture of shrubs. HortScience 1994, 29, 781-784. [CrossRef]

17. Roy, S.; Barman, S.; Chakraborty, U.; Chakraborty, B. Evaluation of Spent Mushroom Substrate as biofertilizer for growth improvement of Capsicum annuum L. J. Appl. Biol. Biotechnol. 2015, 3, 022-027. [CrossRef]

18. Ribas, L.C.C.; de Mendonça, M.M.; Camelini, C.M.; Soares, C.H.L. Use of spent mushroom substrates from agaricus subrufescens (syn. a. blazei, a. brasiliensis) and lentinula edodes productions in the enrichment of a soil-based potting media for lettuce (lactuca sativa) cultivation: growth promotion and soil bioremediation. Bioresour. Technol. 2009, 100, 4750-4757. [CrossRef]

19. Marques, E.L.S.; Martos, E.T.; Souza, R.J.; Silva, R.; Zied, D.C.; Dias, E.S. spent mushroom compost as a substrate for the production of lettuce seedlings. J. Agric. Sci. 2014, 6, 138-143. [CrossRef]

20. Lopes, R.X.; Zied, D.C.; Martos, E.T.; de Souza, R.J.; da Silva, R.; Dias, E.S. Application of spent agaricus subrufescens compost in integrated production of seedlings and plants of tomato. International. J. Recycl. Org. Waste Agric. 2015, 4, 211-218. [CrossRef]

21. Stoknes, K.; Beyer, D.M.; Norgaard, E. Anaerobically digested food waste in compost for Agaricus bisporus and Agaricus subrufescens and its effect on mushroom productivity. J. Sci. Food Agric. 2013, 93, 2188-2200. [CrossRef] [PubMed]

22. Stoknes, K.; Wojciechowska, E.; Jasinska, A.; Gulliksen, A.; Tesfamichael, A.A. Growing vegetables in the circular economy; cultivation of tomatoes on green waste compost and food waste digestate. Acta Hortic. 2018, 1215, 389-396. [CrossRef]

23. Liu, C.J.; Duan, Y.L.; Jin, R.Z.; Han, Y.Y.; Hao, J.H.; Fan, S.X. Spent mushroom substrates as component of growing media for lettuce seedlings. IOP Conf. Ser. Earth Environ. Sci. 2018, 185, 012-016. [CrossRef]

24. Svjetlana, Z.; Parađiković, N.; Šušak, U.; Tkalec, M. Use of spent mushroom substrate for growing geranium (Pelargonium peltatum L.) and surfinia (Petunia hybrida Juss.) seedlings. In Proceedings of the Sixth International Scientific Agricultural Symposium Agrosym 2015, Jahorina, Sarajevo, Bosnia and Herzegovina, 15-18 October 2015.

25. Chong, C.; Cline, R.A.; Rinker, D.; Allen, O.B. Growth and mineral nutrient status of containerized woody species in media amended with spent mushroom compost. J. Am. Soc. Hortic. Sci. 1991, 116, $242-247$. [CrossRef]

26. Young, J.; Holcomb, E.; Heuser, C. Greenhouse growth of marigolds in three leached sources of spent mushroom compost over a 3-year period. Hort Technol. 2002, 12, 701-705. [CrossRef]

27. Jonathan, S.G.; Lawal, M.M.; Oyetunji, O.J. Effect of Spent Mushroom Compost of Pleurotus pulmonarius on Growth Performance of Four Nigerian Vegetables. Mycobiology 2011, 39, 164-169. [CrossRef]

28. Wang, S.H.-L.; Lohr, V.I.; Coffey, D.L. Growth response of selected vegetable crops to spent mushroom compost application in a controlled environment. Plant Soil 1984, 82, 31-40. [CrossRef] 
29. Polat, E.; Uzu, H.; Topçuol, B.; Öna, K.; Onus, A.; Karac, M. Effects of spent mushroom compost on quality and productivity of cucumber (Cucumis sativus L.) grown in greenhouses. Afr. J. Biotechnol. 2009, 8, 176-180.

30. Ahmad, M.; Khan, I.; Shah, B.; Naeem, A.; Khan, N.; Ullah, W.; Adnan, M.; Rizwan, S. Study on the management of Ralstonia solanacearum (Smith) with spent mushroom compost. J. Entomolog. Zool. Stud. 2016, 4, 114-121.

31. Tesfamichael, A.A.; Stoknes, K. Substitution of peat with vermicompost from food waste digestate and green waste compost. Acta Hortic. 2017, 1168, 399-406. [CrossRef]

32. Stoknes, K.; Scholwin, F.; Jasinska, A.; Wojciechowska, E.; Mleczek, M.; Hanc, A.; Niedzielski, P. Cadmium mobility in a circular food-to-waste-to-food system and the use of a cultivated mushroom (Agaricus subrufescens) as a remediation agent. J. Environ. Manag. 2019, 245, 48-54. [CrossRef] [PubMed]

33. Visscher, H. Casing soil. In The Cultivation of Mushrooms; van Griensven, L.J.L.D., Ed.; Darlington Mushroom Laboratories: Sussex, UK, 1988; pp. 73-89.

34. Caesar-Tonthat, T.C.; Espeland, E.; Caesar, A.J.; Sainju, U.M.; Lartey, R.T.; Gaskin, J.F. Effects of agaricus lilaceps fairy rings on soil aggregation and microbial community structure in relation to growth stimulation of western wheatgrass (Pascopyrum smithii) in Eastern Montana rangeland. Microb. Ecol. 2013, 66, 120-131. [CrossRef] [PubMed]

35. Edwards, P.J. Effects of the fairy ring fungus agaricus arvensis on nutrient availability in grassland. New Phytol. 1988, 110, 377-381. [CrossRef]

36. Wolfe, B.E.; Kuo, M.; Pringle, A. Amanita thiersii is a saprotrophic fungus expanding its range in the United States. Mycologia 2012, 104, 22-33. [CrossRef]

37. Guhr, A.; Borken, W.; Spohn, M.; Matzner, E. Redistribution of soil water by a saprotrophic fungus enhances carbon mineralization. Proc. Natl. Acad. Sci. USA 2015, 112, 14647-14651. [CrossRef]

38. Gramss, G. The universe of basidiomycetous ground fungi. In Current Research, Technology and Education Topics in Applied Microbiology and Microbial Biotechnology; Formatex Research Center: Badajoz, Spain, 2010; pp. 218-229.

39. Hildén, K.; Mäkelä, M.R.; Lankinen, P.; Lundell, T. Agaricus bisporus and related Agaricus species on lignocellulose: Production of manganese peroxidase and multicopper oxidases. Fungal Genet. Biol. 2013, 55, 32-41. [CrossRef]

40. Fritsche, G. Tests on breeding with Agaricus arvensis. Mushroom Sci. 1979, 10, 91-101.

41. Noble, R. Alternative Agaricus: The Culture of Agaricus W4 and Agaricus Arvensis; HDC Project, M4b; Horticulture Research International: Wellesbourne, Warwick, UK, 1995; 14p. 